\title{
Post-load hyperglycemia as an important predictor of long-term adverse cardiac events after acute myocardial infarction: a scientific study
}

\author{
Shuichi Kitada ${ }^{1,2 \dagger}$, Yoritaka Otsuka ${ }^{1,3^{*} \dagger}$, Nobuaki Kokubu', Yoichiro Kasahara', Yu Kataoka', Teruo Noguchi ${ }^{1}$,
} Yoichi Goto', Genjirou Kimura², Hiroshi Nonogi ${ }^{1}$

\begin{abstract}
Background: Diabetes mellitus (DM) and impaired glucose tolerance (IGT) are risk factors for acute myocardial infarction (AMI). However, it is unknown whether hyperglycemic state is associated with increased major adverse cardiovascular events (MACE) after AMI. In this study, we evaluated the relationship between glucometabolic status and MACE in patients after AMI, and determined the critical level of $2 \mathrm{~h}$ post-load plasma glucose that may be used to predict MACE.
\end{abstract}

Methods: AMI patients ( $n=422$ ) were divided into 4 groups as follows: normal glucose tolerance (NGT) group, IGT group, newly diagnosed DM (NDM) group, and previously known DM (PDM) group. MACE of the 4 groups were compared for 2 years from AMl onset.

Results: The NDM group had a significantly higher event rate than the IGT and NGT groups and had a similar event rate curve to PDM group. The logistic models analyses revealed that $2 \mathrm{~h}$ post-load plasma glucose values of $\geq 160 \mathrm{mg} / \mathrm{dL}$ was the only independent predictor of long-term MACE after AMI ( $p=0.028$, OR: 1.85, 95\% Cl: 1.073.21). The 2 -year cardiac event rate of patients with a $2 \mathrm{~h}$ post-load hyperglycemia of $\geq 160 \mathrm{mg} / \mathrm{dL}$ was significantly higher than that of patients with $2 \mathrm{~h}$ post-load glucose of $<160 \mathrm{mg} / \mathrm{dL}(32.2 \% \mathrm{vs} .19 .8 \%, \mathrm{p}<0.05)$ and was similar to that of PDM group (37.4\%, $p=0.513)$.

Conclusions: NDM increases the risk of MACE after AMI as does PDM. Particularly, post-AMl patients with a $2 \mathrm{~h}$ post-load hyperglycemia $\geq 160 \mathrm{mg} / \mathrm{dL}$ may need adjunctive therapy after AMI.

\section{Introduction}

It is well known that diabetes mellitus (DM) is an independent risk factor for cardiovascular disease (CVD). The risk of CVD for diabetic patients is two to three times higher than that of subjects without DM [1-4]. In addition, several previous studies have shown that postload hyperglycemia such as impaired glucose tolerance (IGT) is a risk factor for CVD [5-7]. In patients with acute myocardial infarction (AMI), the prevalence of abnormal glucose tolerance (AGT) using an oral glucose tolerance test (OGTT) was $>70 \%$ [8-11]. In the GAMI (Glucose Abnormalities in Patients with Myocardial

\footnotetext{
* Correspondence: yotsuka@f-wajirohp.jp

† Contributed equally

${ }^{1}$ Department of Cardiology, National Cardiovascular Center, Osaka, Japan Full list of author information is available at the end of the article
}

Infarction) study and the report by Tamita et al, AGT including IGT and newly diagnosed DM (NDM) were strong predictors of major adverse cardiac events (MACE) after AMI [12,13].

The risk for poor long-term prognosis after AMI may be already apparent if patients have post-load hyperglycemia even at plasma glucose level well below the diabetic threshold. The threshold for definition of DM is primarily based on a post-load two-hour $(2 \mathrm{~h})$ plasma glucose level in patients with diabetic retinopathy. Hence, cardiovascular disease has not been considered as a factor in the classification of glucose tolerance abnormality.

In the current study, we performed a retrospective analysis of patients with AMI whose glucose tolerance were assessed by using a $75 \mathrm{~g}$ OGTT, and evaluated the 
relationship between their glucometabolic status and long-term MACE. We also determined the critical level of the $2 \mathrm{~h}$ post-load plasma glucose to predict the occurrence of MACE.

\section{Methods}

\section{Study Patients}

Between January 2000 and December 2004, a total of 763 patients with first AMI were admitted to the National Cardiovascular Center (Osaka, Japan). Of the 763 patients admitted, 422 patients who received glucose tolerance tests or were previously known to have DM were evaluated for cardiac events for two years.

The diagnosis of AMI was based on the presence of typical chest pain, ST-segment change or new Q-waves in the 12-lead electrocardiogram, an increase of $\geq 2$-fold over the upper limit of normal in creatine kinase concentration, local asynergy of left ventricular wall on ultrasound cardiography or left ventriculography, or occlusion of coronary artery on coronary angiography. Patients with transient left ventricular ballooning syndrome, vasospasm, spontaneous coronary artery dissection, thromboembolism, catheter related complications, left main trunk infarction, type 1 diabetes mellitus or familial hyperlipidemia were excluded from the study.

\section{Classification of abnormal glucose tolerance}

Glucose abnormalities of study patients were classified into 4 groups using a $75 \mathrm{~g}$ OGTT according to the criteria for glucometabolic disturbances established by the World Health Organization (WHO). This was because we first started to evaluate abnormal glucose tolerance using a 75 g OGTT in patients after AMI in year 2000 [14,15]. Only 4 Patients with impaired fasting glucose tolerance were defined as IGT according to Japanese diabetes criteria. A $75 \mathrm{~g}$ OGTT was performed in the stable phase of AMI (median: 9 days from the onset of AMI). Previously known DM (PDM) patients were defined as those with clinical history of using oral hypoglycemic agents and/or insulin and patients with fasting plasma glucose levels $\geq 126 \mathrm{mg} / \mathrm{dL}$. The other patients were urged to evaluate their glucose tolerance by a $75 \mathrm{~g}$ OGTT. NDM was defined as fasting glucose level $<126 \mathrm{mg} / \mathrm{dL}$ and a $2 \mathrm{~h}$ post-load glucose level $\geq 200 \mathrm{mg} / \mathrm{dL}$. Normal glucose tolerance (NGT) was defined as fasting glucose level $<110 \mathrm{mg} /$ $\mathrm{dL}$ and a $2 \mathrm{~h}$ post-load glucose level $<140 \mathrm{mg} / \mathrm{dL}$. In the remaining patients, IGT was defined as fasting glucose level $<126 \mathrm{mg} / \mathrm{dL}$ and a $2 \mathrm{~h}$ post-load glucose level $\geq 140$ $\mathrm{mg} / \mathrm{dL}$ or with fasting glucose level of $110-125 \mathrm{mg} / \mathrm{dL}$ and a $2 \mathrm{~h}$ post-load glucose level $<140 \mathrm{mg} / \mathrm{dL}$.

\section{Data Collection}

All patients who survived the acute phase ( $\leq 30$ days) were followed-up at the outpatient clinic and their data for MACE were collected. Three patients with PDM died during the acute phase. In this study, a total of 422 patients were followed-up for two years. Patients' outcomes were assessed on the basis of MACE, which included death from cardiovascular causes, nonfatal AMI, hospitalization for heart failure and revascularization for restenosis and de novo lesions. Revascularization was performed after obtaining ischemic evidence by several modalities.

To determine the predictors of long-term MACE, the baseline clinical characteristics of the patients including laboratory data, characteristics of AMI, and medications (Table 1) were evaluated using hospital records under the auspices of the institutional cardiovascular outcomes monitoring program.

\section{Statistical Analyses}

SPSS Software version 17.0 (Chicago, USA) was used for all statistical analyses. Continuous variables were expressed as mean \pm standard deviation (SD). Statistical significance was evaluated using unpaired Student's $t$ test for comparisons between two means, and a chisquare test for categorical data. Event-free survival curves were constructed using the Kaplan-Meier survival methods and were compared with log-rank statistics. Survival time was defined as the intervals between the onset of AMI and the time of MACE. Receiver-operating characteristic (ROC) analysis was performed to define sensitivity and specificity of $2 \mathrm{~h}$ post-load plasma glucose. In addition, ROC analysis was used as an exploratory evaluation of the best cut-off point of $2 \mathrm{~h}$ post-load plasma glucose to predict MACE after AMI in non-PDM patients and positive and negative predictive values were derived using this cut-off value. Logistic regression analysis was used to identify predictors of cardiac events. A $p$ value of $<0.05$ was considered statistically significant.

\section{Results}

\section{Clinical backgrounds and prevalence of glucose abnormalities}

Figure 1 shows a flow diagram for the enrollment of patients into this study. Of the total 763 patients, we excluded a total of 247 patients; 48 patients for etiology of AMI, 11 patients for clinical history of type1 DM and familial hyperlipidemia, and 188 patients who did not consent to have the $75 \mathrm{~g}$ OGTT. Three patients with PDM died during the acute phase ( $\leq 30$ days) after AMI. In all, 422 patients completed two years of follow-up from onset; 91 patients dropped out during the study and did not complete the two years of follow up. The clinical characteristics of the patients who completed the study are shown in Table 1. The PDM group had a higher mean age, and a higher prevalence of 
Table 1 Clinical Characteristics of Study Patients

\begin{tabular}{|c|c|c|c|c|}
\hline & $\begin{array}{c}\text { NGT } \\
(n=106)\end{array}$ & $\begin{array}{c}\text { IGT } \\
(n=140)\end{array}$ & $\begin{array}{c}\text { NDM } \\
(n=68)\end{array}$ & $\begin{array}{c}\text { PDM } \\
(n=108)\end{array}$ \\
\hline \multicolumn{5}{|l|}{ Basic characteristics } \\
\hline Male, n (\%) & $77(72.6)$ & $108(77.1)$ & $56(82.4)$ & $86(79.6)$ \\
\hline Age, year & $64 \pm 11$ & $66 \pm 10$ & $63 \pm 11$ & $68 \pm 9 . * * * *$ \\
\hline Body-mass index, $\mathrm{kg} / \mathrm{m}^{2}$ & $23.4 \pm 3.0$ & $23.5 \pm 2.6$ & $24.5 \pm 2.7^{* * *}$ & $24.2 \pm 2.9^{* * *}$ \\
\hline Family history of IHD, $\mathrm{n}(\%)$ & $30(28.3)$ & 45(32.1) & $19(27.9)$ & $26(24.1)$ \\
\hline History of smoking, n (\%) & $80(75.5)$ & $99(70.7)$ & $56(82.4)$ & $79(73.1)$ \\
\hline \multicolumn{5}{|l|}{ Clinical history, n (\%) } \\
\hline Hypertension, n (\%) & $66(62.3)$ & $82(58.6)$ & $41(60.3)$ & $63(58.3)$ \\
\hline Hyperlipidemia, n (\%) & $62(58.5)$ & $84(60.0)$ & $44(64.7)$ & $62(57.4)$ \\
\hline Heart failure, n (\%) & $2(1.9)$ & $2(1.4)$ & $0(0.0)$ & $2(1.9)$ \\
\hline Cerebrovascular disease, $\mathrm{n}(\%)$ & $4(3.8)$ & $12(8.6)$ & $2(2.9)$ & $13(12.0)^{*}$ \\
\hline Chronic renal failure, n (\%) & $2(1.9)$ & $9(6.4)$ & $1(1.5)$ & $9(8.3)$ \\
\hline ASO, n (\%) & $5(4.7)$ & $6(4.3)$ & $4(5.9)$ & $17(15.7)^{* * *}$ \\
\hline Chronic obstructive pulmonary disease, n (\%) & $2(1.9)$ & $5(3.6)$ & $1(1.5)$ & $1(0.9)$ \\
\hline Malignancy, n (\%) & $4(3.8)$ & $11(7.9)$ & $3(4.4)$ & $3(2.8)$ \\
\hline Previous procedures (PTCA/CABG), n (\%) & $3(2.8)$ & $7(5.0)$ & $6(8.8)$ & $8(7.4)$ \\
\hline \multicolumn{5}{|l|}{ Laboratory data at the time of admission } \\
\hline Fasting blood sugar, mg/dL & $90 \pm 7$ & $94 \pm 9 .^{*}$ & $99 \pm 11^{* * *}$ & \\
\hline Blood sugar after $2 \mathrm{~h}, \mathrm{mg} / \mathrm{dL}$ & $115 \pm 18$ & $165 \pm 20^{*}$ & $237 \pm 30 * * *$ & \\
\hline $\mathrm{HbA} 1 \mathrm{c}, \%$ & $5.3 \pm 0.3$ & $5.4 \pm 0.5^{*}$ & $5.7 \pm 0.4^{* * *}$ & $8.1 \pm 1.5^{* * * * *}$ \\
\hline Total Cholesterol, mg/dL & $194 \pm 39$ & $193 \pm 37$ & $199 \pm 33$ & $199 \pm 42$ \\
\hline Triglyceride, mg/dL & $107 \pm 85$ & $102 \pm 56$ & $123 \pm 74^{* *}$ & $122 \pm 87^{* *}$ \\
\hline LDL-Cholesterol, mg/dL & $130 \pm 37$ & $130 \pm 32$ & $129 \pm 33$ & $130 \pm 36$ \\
\hline HDL-Cholesterol, mg/dL & $44 \pm 11$ & $43 \pm 12$ & $45 \pm 20$ & $45 \pm 12$ \\
\hline Serum creatinine, mg/dL & $0.8 \pm 0.2$ & $0.8 \pm 0.3$ & $0.8 \pm 0.2$ & $0.9 \pm 0.3$ \\
\hline Urea acid, mg/dL & $5.3 \pm 1.5$ & $5.5 \pm 1.6$ & $5.6 \pm 1.3$ & $5.2 \pm 1.8$ \\
\hline \multicolumn{5}{|l|}{ Characteristics of acute myocardial infarction } \\
\hline Systolic blood pressure on admission, $\mathrm{mmHg}$ & $135 \pm 25$ & $139 \pm 23$ & $139 \pm 24$ & $136 \pm 24$ \\
\hline Heart rate on admission, bpm/m & $72 \pm 17$ & $75 \pm 16$ & $76 \pm 18$ & $77 \pm 19$ \\
\hline 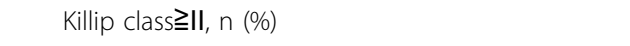 & $9(8.5)$ & $5(3.6)$ & $4(5.9)$ & $15(13.9)^{* *}$ \\
\hline Anterior Ml, n (\%) & $45(42.5)$ & $77(55.0)$ & $28(41.2)$ & $50(46.3)$ \\
\hline Multi-vessel disease, n (\%) & $48(45.3)$ & $63(45.0)$ & $35(51.5)$ & $73(67.6)^{* * * * * *}$ \\
\hline \multicolumn{5}{|l|}{ Procedural features } \\
\hline Thrombolysis, n (\%) & $16(15.1)$ & 19 (13.6) & $7(10.3)$ & $14(13.0)$ \\
\hline Primary PTCA/CABG, n (\%) & $64(60.4)$ & $96(68.6)$ & $45(66.2)$ & $61(56.5)$ \\
\hline Stent implantation, n (\%) & 73(68.9) & $116(82.9)^{*}$ & $52(76.5)$ & $68(63.0)$ \\
\hline LVEF, \% & $44.4 \pm 8.1$ & $42.8 \pm 8.2$ & $43.9 \pm 8.8$ & $43.6 \pm 9.2$ \\
\hline Peak CPK, U/L & $2827 \pm 1905$ & $2988 \pm 2385$ & $2741 \pm 1588$ & $2757 \pm 2393$ \\
\hline \multicolumn{5}{|l|}{ Medications } \\
\hline Aspirin, $\mathrm{n}(\%)$ & 103(97.2) & 138 (98.6) & $66(97.1)$ & $104(96.3)$ \\
\hline ACEI/ARB, n (\%) & $72(67.9)$ & $104(74.3)$ & $54(79.4)$ & $73(67.6)$ \\
\hline Beta-blockers, n (\%) & $46(43.4)$ & $87(62.1)^{*}$ & $45(66.2)^{*}$ & $63(58.3)^{*}$ \\
\hline Statin, n (\%) & $46(43.4)$ & $65(46.4)$ & $39(57.4)$ & $45(41.2)$ \\
\hline Oral hypoglycemic agents, n (\%) & $0(0)$ & $0(0)$ & $2(2.9)$ & $66(61.1)^{* * * * * *}$ \\
\hline Insulin therapy, n (\%) & $0(0)$ & $0(0)$ & $0(0)$ & $18(16.7)^{* * * * * *}$ \\
\hline
\end{tabular}

*; vs NGT $p<0.05 * *$; vs IGT $p<0.05 * * *$ vs NDM $p<0.05$.

NGT, normal glucose tolerance; IGT, impaired glucose tolerance; NDM, newly diagnosed diabetes mellitus; PDM, previously known diabetes mellitus; IHD, ischemic heart disease; ASO, arteriosclerosis obliterans; PTCA, percutaneous transluminal coronary angioplasty; CABG, coronary artery bypass grafting; HbA1c, hemoglobin A1c; LDL-Cholesterol, low-density lipoprotein cholesterol; HDL-Cholesterol, high-density lipoprotein Cholesterol; MI = myocardial infarction; LVEF, left ventricular ejection fraction; CPK, creatine phosphokinase; ACEl, angiotensin-converting enzyme inhibitor; ARB, angiotensin II receptor blocker. 


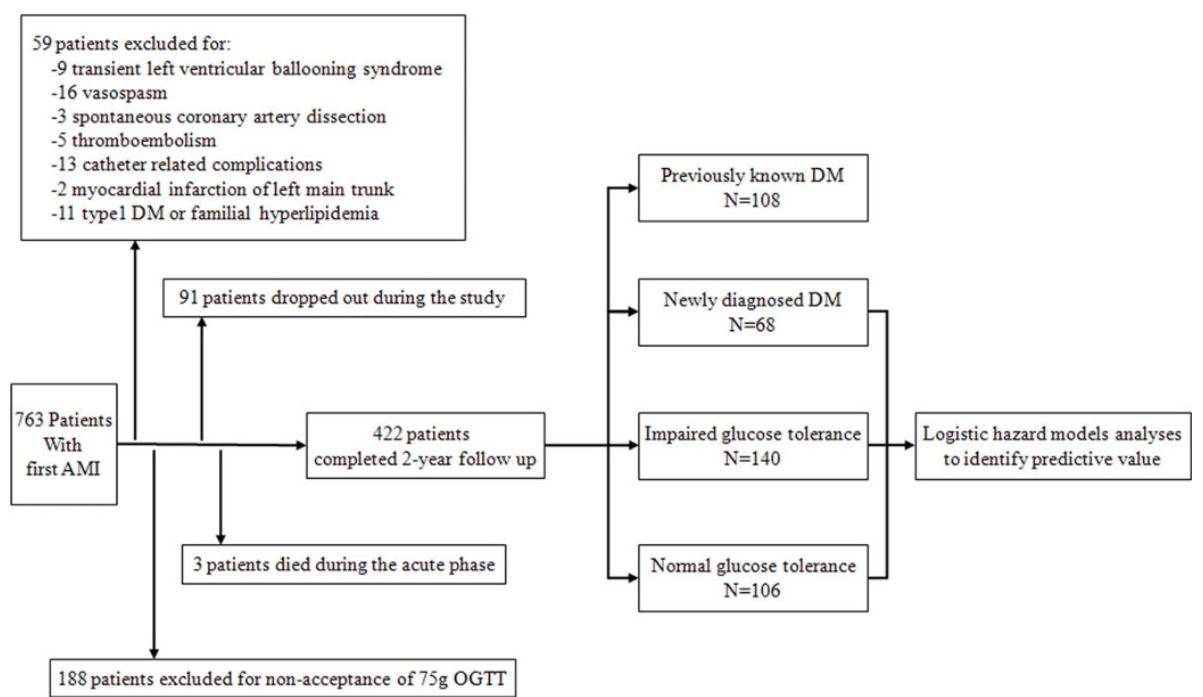

Figure 1 Study profile

co-morbidities and incidence of multi-vessel disease compared with the other groups. The NDM and PDM groups had higher body-mass index and serum triglyceride levels compared with the NGT and IGT groups. The level of HbA1c of the NDM group was significantly lower than that of the PDM group $(5.7 \pm 0.4 \mathrm{mg} / \mathrm{dL}$ vs. $8.1 \pm 1.5 \mathrm{mg} / \mathrm{dL}, \mathrm{p}<0.05)$. Only $2.9 \%$ of patients in the NDM group were being treated by oral hypoglycemic agents, while $61.1 \%$ and $16.7 \%$ of patients in the PDM group were being treated by oral hypoglycemic agents and insulin therapy, respectively. The prevalence of NGT, IGT, NDM, and PDM was $25 \%, 32 \%, 16 \%$, and $26 \%$, respectively.

Of the 310 patients who were tested with $75 \mathrm{~g}$ OGTT, 204 patients (66\%) showed post-load hyperglycemia of $\geq 140 \mathrm{mg} / \mathrm{dL}$. Only 4 patients showed impaired fasting glucose tolerance with a fasting blood glucose level of $110 \mathrm{mg} / \mathrm{dL}$ to $126 \mathrm{mg} / \mathrm{dL}$.

\section{Long-term MACE}

Long-term MACE were observed in 120 patients. Table 2 shows the numbers of long-term MACE among study patients. There were 40 cardiovascular events in the PDM group, 24 events in the NDM group, 32 events in the IGT group, and 24 events in the NGT group. The 2 -year cumulative event free rates from MACE were 63.0\% for the PDM group, $64.7 \%$ for the NDM group, $77.1 \%$ for the IGT group, and $77.4 \%$ for the NGT group. Figure 2 shows Kaplan-Meier plots of study patients with MACE during the 2-year follow-up period. The PDM group and the NDM group showed significantly higher event rates than non-diabetic patients and the NDM group had a similar event rate to the PDM group. There was no significant difference in event free rate between the IGT group and the NGT group during the follow-up period.

\section{Predictors of long-term MACE}

The clinical characteristics were compared between non-PDM patients with and without MACE (Table 3). There was no significant difference in long-term MACE rate between non-PDM patients with and without MACE although the $2 \mathrm{~h}$ post-load plasma glucose appeared to be related to the occurrence of MACE. Logistic analyses were carried out to examine an independent predictive value of the $2 \mathrm{~h}$ post-load plasma glucose level for long-term MACE. The adjusted variables were the 5 factors that were previously reported to

Table 2 Long-term MACE in Patients with Acute Myocardial Infarction during 2-year Follow-up

\begin{tabular}{lcccc}
\hline & \multicolumn{4}{c}{$\begin{array}{c}\text { Long-term MACE } \\
\text { (>30 days) }\end{array}$} \\
\cline { 2 - 5 } & NGT & IGT & NDM & PDM \\
\cline { 2 - 5 } & $\mathbf{1 0 6}$ & $\mathbf{1 4 0}$ & $\mathbf{6 8}$ & $\mathbf{1 0 8}$ \\
\hline Cardiac death, n (\%) & 0 & 0 & 0 & $4(4)$ \\
Non-fatal acute myocardial infarction, & 0 & $2(1)$ & $2(3)$ & $1(1)$ \\
n (\%) & & & & \\
Hospitalization for heart failure, n (\%) & $3(3)$ & $3(2)$ & $1(1)$ & $4(4)$ \\
Revascularization & & & & \\
$\quad$ Target vessel revascularization, n (\%) & 18 & 20 & 19 & 25 \\
$\quad(17)$ & $(14)$ & $(28)$ & $(23)$ \\
$\quad$ Revascularization to de novo lesion, & $3(3)$ & $7(5)$ & $2(3)$ & $6(6)$ \\
n (\%) & & & & \\
\hline Total MACE, n (\%) & 24 & 32 & 24 & 40 \\
& $(23)$ & $(23)$ & $(35)$ & $(37)$ \\
\hline
\end{tabular}

MACE, major adverse cardiovascular events; NGT, normal glucose tolerance; IGT, impaired glucose tolerance; NDM, newly diagnosed diabetes mellitus; PDM, previously known diabetes mellitus. 


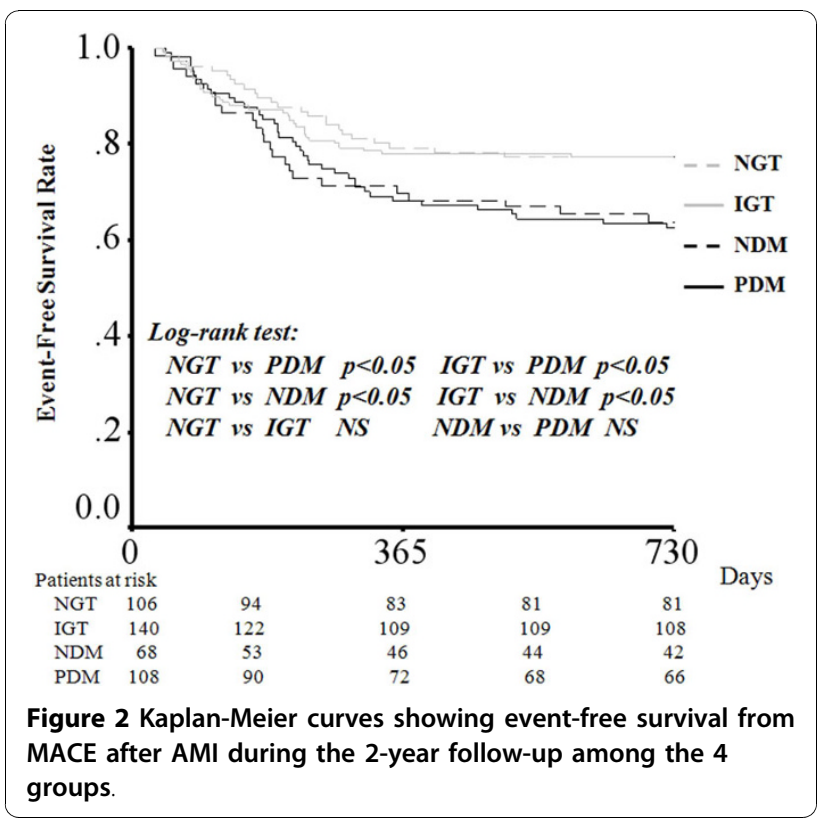

be related to MACE: age, left ventricular ejection fraction, multi-vessel disease, use of beta-blockers, and statin use.

The ROC analysis indicated that a cut-off value of $2 \mathrm{~h}$ post-load plasma glucose level $\geq 160 \mathrm{mg} / \mathrm{dL}$ best predicted MACE in non-PDM patients. This measure of post-load glucose value showed a sensitivity and specificity of $59 \%$ and $58 \%$, respectively. The positive and negative predictive values of $2 \mathrm{~h}$ post-load plasma glucose level $\geq 160 \mathrm{mg} / \mathrm{dL}$ were $32 \%$ and $80 \%$, respectively. The odds ratio of $2 \mathrm{~h}$ post-load plasma glucose values for MACE was 1.85 (95\% CI: 1.07-3.21) for patients with glucose level $\geq 160 \mathrm{mg} / \mathrm{dL}$. The logistic models analyses revealed that $2 \mathrm{~h}$ post-load plasma glucose values of $\geq 160 \mathrm{mg} / \mathrm{dL}$ was the only independent predictor of long-term MACE after AMI ( $\mathrm{p}=0.028$, OR: $1.85,95 \%$ CI: 1.07-3.21). Event-free survival rate was also compared between patients with $2 \mathrm{~h}$ post-load plasma glucose $\geq 160 \mathrm{mg} / \mathrm{dL}$ vs. $<160 \mathrm{mg} / \mathrm{dL}$, and patients with $2 \mathrm{~h}$ post-load plasma glucose $\geq 160 \mathrm{mg} / \mathrm{dL}$ vs. PDM group. The 2-year event-free rate of patients with $2 \mathrm{~h}$ post-load plasma glucose $\geq 160 \mathrm{mg} / \mathrm{dL}$ was significantly higher than that of patients with post-load plasma glucose $<160 \mathrm{mg} / \mathrm{dL}(67.8 \%$ vs. $80.2 \%, \mathrm{p}<0.05)$ and was similar to that of PDM group $(62.6 \%, \mathrm{p}=0.513)$ (Figure 3).

\section{Discussion}

\section{Relationship between glucometabolic status and long-} term MACE

During the 2-year follow-up, the incidence of cardiovascular events after AMI was $37.0 \%$ in patients with PDM and $35.3 \%$ in patients with NDM. Both groups had similarly increased risk of long-term MACE after AMI and significantly higher incidence of MACE compared with non-diabetic patients including IGT patients. When baseline characteristics were compared between the NDM and PDM groups, the level of HbA1c of NDM group was significantly lower than that of PDM group $(5.7 \pm 0.4 \mathrm{mg} / \mathrm{dL}$ vs. $8.1 \pm 1.5 \mathrm{mg} / \mathrm{dL}, \mathrm{p}<0.05)$. These results indicate that patients with diabetes may have an increased risk of cardiovascular events after AMI irrespective of diabetic status such as severity or disease duration of DM. Therefore, early detection of NDM using a $75 \mathrm{~g}$ OGTT after AMI may be important in the risk assessment of cardiac events.

Several previous epidemiological studies have indicated that even patients with pre-diabetic conditions, below the diabetic threshold, are at high risk of cardiovascular disease [5-7]. The GAMI study and a study by Tamita et al [13] showed that AGT including IGT and NDM was a risk factor of increased cardiac events after AMI [12,13]. However, it is unclear whether patients with post-load hyperglycemia below the threshold for DM after AMI have a risk of long-term cardiovascular events. The Euro Heart Survey has reported that PDM or NDM, but not IGT, has a negative influence on the 1-year outcome in patients with coronary artery disease [16]. In the current study, we similarly demonstrated that NDM is a factor for increased risk of cardiac events as is PDM after AMI, but there was no significant difference for long-term MACE between IGT and NGT patients.

\section{Predictive value of $2 \mathrm{~h}$ post-load plasma glucose for long- term MACE}

We demonstrated that patients with a $2 \mathrm{~h}$ post-load plasma glucose value $\geq 160 \mathrm{mg} / \mathrm{dL}$, including patients with plasma glucose value consistent with DM, had a significantly higher risk of long-term MACE after AMI than the patients with post-load glucose value $<160 \mathrm{mg} /$ $\mathrm{dL}$. Although we demonstrated NDM patients had an increased risk of cardiac events after AMI in the present study, we confirmed that patients with post-load hyperglycemia ( $\geq 160 \mathrm{mg} / \mathrm{dL}$ ) had increased risk of poor longterm outcomes after AMI. Previous investigators have suggested several potential predictors for long-term cardiovascular events in patients with AMI, including impaired left ventricular function, residual ischemia, and pharmacological therapy [17-25]. Even after adjustment for previously proposed predictors and age, we found that a $2 \mathrm{~h}$ post-load plasma glucose level $\geq 160 \mathrm{mg} / \mathrm{dL}$ is another potential predictor of long-term cardiovascular events after AMI. The cut-off points for DM on fasting and $2 \mathrm{~h}$ post-load glucose values were primarily determined based on the prevalence of microvascular disease related to hyperglycemic complications like diabetic retinopathy. We may need to reconsider the thresholds 
Table 3 Comparison of Clinical Characteristics between Patients with and without Adverse Cardiovascular Events not Previously Known to have Diabetes Mellitus

\begin{tabular}{|c|c|c|c|}
\hline & $\begin{array}{l}\text { Patientswith Cardiovascular Events } \\
\qquad(\mathrm{n}=\mathbf{8 0})\end{array}$ & $\begin{array}{l}\text { Patients without Cardiovascular Events } \\
\qquad(\mathrm{n}=234)\end{array}$ & $\mathrm{p}$ value \\
\hline \multicolumn{4}{|l|}{ Basic characteristics } \\
\hline Male, n (\%) & $59(73.8)$ & $182(78.1)$ & 0.44 \\
\hline Age, year & $64 \pm 11$ & $64 \pm 10$ & 0.91 \\
\hline Body-mass index, $\mathrm{kg} / \mathrm{m}^{2}$ & $23.5 \pm 2.8$ & $23.7 \pm 2.8$ & 0.71 \\
\hline Family history of IHD, $\mathrm{n}(\%)$ & $26(32.5)$ & $68(29.2)$ & 0.58 \\
\hline History of smoking, n (\%) & $58(72.5)$ & $177(76.0)$ & 0.55 \\
\hline \multicolumn{4}{|l|}{ Clinical history } \\
\hline Hypertension, n (\%) & $45(56.3)$ & $144(61.8)$ & 0.43 \\
\hline Hyperlipidemia, n (\%) & $52(65.0)$ & $137(58.8)$ & 0.36 \\
\hline Heart failure, n (\%) & $1(1.3)$ & $3(1.3)$ & $>0.99$ \\
\hline Cerebrovascular disease, $\mathrm{n}(\%)$ & $4(5.0)$ & $14(6.0)$ & $>0.99$ \\
\hline Chronic renal failure, $\mathrm{n}(\%)$ & $2(2.5)$ & $10(4.3)$ & 0.74 \\
\hline ASO, n (\%) & $6(7.5)$ & $9(3.9)$ & 0.22 \\
\hline Chronic obstructive pulmonary disease, n (\%) & $1(1.3)$ & $7(3.0)$ & 0.69 \\
\hline Malignancy, n (\%) & $5(6.3)$ & $12(5.2)$ & 0.78 \\
\hline Previous procedures (PTCA/CABG), n (\%) & $6(7.5)$ & $10(4.3)$ & 0.25 \\
\hline \multicolumn{4}{|l|}{ Laboratory data at the time of admission } \\
\hline Fasting blood sugar, mg/dL & $95 \pm 9$ & $94 \pm 10$ & 0.45 \\
\hline Blood sugar after $2 \mathrm{~h}, \mathrm{mg} / \mathrm{dL}$ & $172 \pm 51$ & $160 \pm 49$ & 0.07 \\
\hline $\mathrm{HbA} 1 \mathrm{c}, \%$ & $5.4 \pm 0.5$ & $5.4 \pm 0.4$ & 0.75 \\
\hline Total Cholesterol, mg/dL & $198 \pm 34$ & $194 \pm 38$ & 0.34 \\
\hline Triglyceride, mg/dL & $109 \pm 73$ & $107 \pm 71$ & 0.85 \\
\hline LDL-Cholesterol, mg/dL & $134 \pm 34$ & $128 \pm 34$ & 0.18 \\
\hline HDL-Cholesterol, mg/dL & $42 \pm 9$ & $44 \pm 15$ & 0.16 \\
\hline Serum creatinine, mg/dL & $0.8 \pm 0.2$ & $0.8 \pm 0.3$ & 0.66 \\
\hline Urea acid, mg/dL & $5.4 \pm 1.6$ & $5.5 \pm 1.5$ & 0.75 \\
\hline \multicolumn{4}{|l|}{ Characteristics of acute myocardial infarction } \\
\hline Systolic blood pressure on admission, $\mathrm{mmHg}$ & $136 \pm 26$ & $138 \pm 23$ & 0.65 \\
\hline Heart rate on admission, bpm/m & $77 \pm 18$ & $73 \pm 16$ & 0.14 \\
\hline Killip class $\geqq I I, ~ n(\%)$ & $7(8.8)$ & $11(4.7)$ & 0.26 \\
\hline Anterior Ml, n (\%) & $42(52.5)$ & $108(46.4)$ & 0.37 \\
\hline Multi-vessel disease, n (\%) & $42(52.5)$ & $104(44.6)$ & 0.24 \\
\hline \multicolumn{4}{|l|}{ Procedural features } \\
\hline Thrombolysis, n (\%) & $12(15.0)$ & $30(12.9)$ & 0.7 \\
\hline Primary PTCA/CABG, n (\%) & $47(58.8)$ & $158(67.8)$ & 0.17 \\
\hline Stent implantation, n (\%) & $63(78.8)$ & $178(76.4)$ & 0.75 \\
\hline LVEF, \% & $42.2 \pm 8.5$ & $44.0 \pm 8.2$ & 0.11 \\
\hline Peak CPK, U/L & $2965 \pm 1836$ & $2857 \pm 2154$ & 0.71 \\
\hline \multicolumn{4}{|l|}{ Medications } \\
\hline Aspirin, $\mathrm{n}(\%)$ & 79 (98.8) & $227(97.4)$ & 0.68 \\
\hline ACEI/ARB, n (\%) & $59(73.8)$ & $171(73.4)$ & $>0.99$ \\
\hline Beta-blockers, n (\%) & $53(66.3)$ & $125(53.6)$ & 0.07 \\
\hline Statin, n (\%) & $37(46.3)$ & $112(48.1)$ & 0.8 \\
\hline Oral hypoglycemic agents, n (\%) & $1(1.3)$ & $1(0.4)$ & 0.45 \\
\hline
\end{tabular}

$\mathrm{IHD}$, ischemic heart disease; ASO, arteriosclerosis obliterans; PTCA, percutaneous transluminal coronary angioplasty; CABG, coronary artery bypass grafting; HbA1C hemoglobin A1c; LDL-Cholesterol, low-density lipoprotein cholesterol; HDL-Cholesterol, high-density lipoprotein Cholesterol; MI, myocardial infarction; LVEF, left ventricular ejection fraction; CPK, creatine phosphokinase; ACEl, angiotensin-converting enzyme inhibitor; ARB, angiotensin II receptor blocker. 


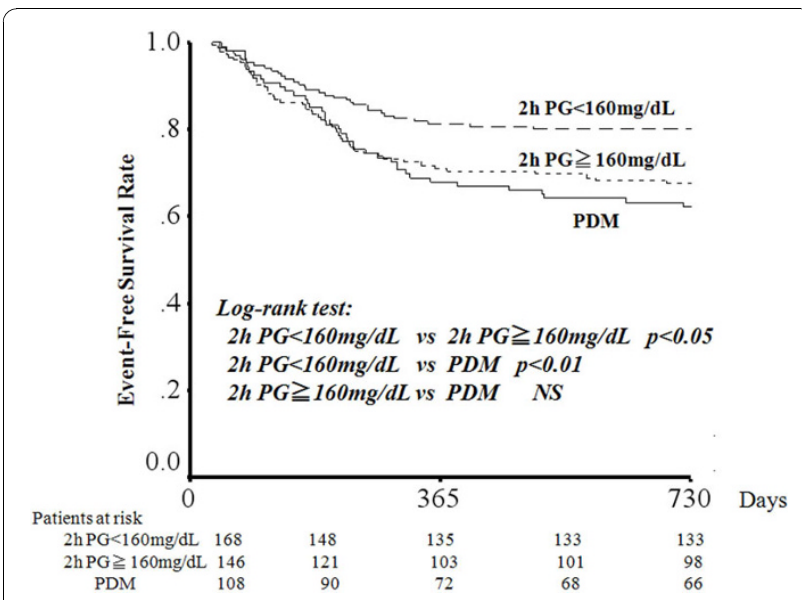

Figure 3 Kaplan-Meier curves showing event-free survival from MACE after AMI among patients with $2 \mathrm{~h}$ post-load plasma glucose $\geq 160 \mathrm{mg} / \mathrm{dL}$, with $2 \mathrm{~h}$ post-load plasma glucose $<160$ $\mathrm{mg} / \mathrm{dL}$, and with previously known DM.

used to diagnose post-load hyperglycemia for macrovascular disease or cardiac events after AMI.

\section{Relationship between long-term MACE and post-load hyperglycemia}

Previous studies have shown that elevated plasma glucose adversely affects endothelium-dependent vasodilation, inflammatory responses, and increases oxidative stress on the cardiovascular system [26-30]. These hyperglycemic stresses may appear below the threshold glucose level for DM and play an important role for promoting cardiovascular events after AMI. Fasting glucose and glycated haemoglobin provide no information on glucose metabolism after glucose load. It is important to use an OGTT to evaluate glucose tolerance among patients with AMI [31,32]. Because we demonstrated that patients with a glucose value $\geq 160 \mathrm{mg} / \mathrm{dL}$ had a high risk of long-term MACE, similar to the PDM group, early detection of post-load hyperglycemia of $\geq 160 \mathrm{mg} / \mathrm{dL}$ using an OGTT may be useful in the risk management of patients with AMI. In addition, adjunctive therapy for these patients may improve long-term cardiac events after AMI. Further study is needed to confirm this observation.

\section{Usefulness of OGTT for patients with AMI}

In the current study, $74 \%$ of the study patients showed abnormal glucose tolerance (32\% for IGT, 16\% for NDM, 26\% for PDM). Recent studies have shown that NDM and IGT are common among patients with coronary artery disease including acute coronary syndrome [8-11,33,34]. According to the European registry, when patients with AMI, but without PDM, were challenged with an OGTT, about $65 \%$ showed abnormal glucose regulation [33]. We found that $74 \%$ of study patients had abnormal glucose tolerance, which was similar to the $65 \%$ reported previously [33].

\section{Clinical perspectives of intervention for post-load hyperglycemia}

Although several previous studies have confirmed that post-load hyperglycemia or impaired fasting glucose increases cardiovascular disease morbidity and mortality [35-37], it is still unknown whether lifestyle modification and medication for hyperglycemia would reduce this risk. However, in the report from the Euro Heart Survey on Diabetes and the Heart [38], it has been noted that lowering blood glucose using metformin may reduce the risk of cardiovascular events among patients with DM. According to the PROACTIVE Study [39], pioglitazone significantly reduced the occurrence of cardiovascular events in patients with DM who have a high risk of macrovascular events. Recently, preliminary data have shown that there was a pronounced decrease in cardiovascular events in patients with NDM prescribed glucose-lowering drugs compared with those not receiving such treatment [38]. On the other hand, it has not been ascertained that for patients with IGT such interventions also reduce the risk of cardiovascular events. The STOP-NIDDM study [40] showed that the rate of cardiovascular events was significantly reduced in the patients with IGT who received acarbose compared with placebo. In a further study, we have to address the issue of whether the control of post-load hyperglycemia would reduce the risk of recurrence of cardiovascular events after AMI.

\section{Study limitations}

This study was a nonrandomized retrospective analysis based on a small number of patients in a single center. Therefore, our results may not reflect the real world population. Second, we excluded from the study 188 patients $(25 \%)$ who did not consent to have the $75 \mathrm{~g}$ OGTT. Enrolling more patients who consent to having the $75 \mathrm{~g}$ OGTT might make the results more convincing. In this study, we evaluated glucose tolerance of study patients at only two time points, fasting and $2 \mathrm{~h}$ post-load, using a $75 \mathrm{~g}$ OGTT. Estimating of post-load hyperglycemia and parameters such as plasma insulin level could better clarify the relationship of post-load hyperglycemia and cardiovascular events after AMI [41]. Large randomized prospective clinical trials are needed to support our conclusions.

\section{Conclusions}

NDM increases the risk of MACE after AMI as does PDM. NDM and PDM patients have a similar poor prognosis for MACE after AMI. Particularly, post-AMI 
patients with a $2 \mathrm{~h}$ post-load hyperglycemia $\geq 160 \mathrm{mg} / \mathrm{dL}$ may need adjunctive therapy after AMI.

\author{
Abbreviations \\ DM: diabetes mellitus; CVD: cardiovascular disease; IGT: impaired glucose \\ tolerance; AMI: is acute myocardial infarction; AGT: abnormal glucose \\ tolerance; OGTT: oral glucose tolerance test; WHO: World Health \\ Organization; PDM: previously known DM; NDM: newly diagnosed DM; NGT: \\ normal glucose tolerance; MACE: major adverse cardiac events.
}

\section{Acknowledgements}

We would like to thank Mrs Hiromi Maeda for her excellent secretarial assistance, and the nurses and residents in the coronary care unit of the National Cardiovascular Center for their cooperation.

\section{Author details}

'Department of Cardiology, National Cardiovascular Center, Osaka, Japan. ${ }^{2}$ Department of Cardio-Renal Medicine and Hypertension, Nagoya City University Graduate School of Medical Sciences, Aichi, Japan. ${ }^{3}$ Department of Cardiology, Fukuoka Wajiro Hospital, Fukuoka, Japan.

\section{Authors' contributions}

SK has made substantial contributions to acquisition, analysis and interpretation of data, and has been involved in drafting the manuscript. YO has made substantial contributions to conception and design and has been involved in revising the manuscript critically for important intellectual content. NK, YK, YK, TN, YG, GK and HN have been involved in revising the manuscript critically for important intellectual content. All authors have given final approval of the version to be published.

\section{Authors' information}

SK: Interventional Cardiologist

YO: Interventional Cardiologist, FACC, FESC, and Director of catheterization laboratory

NK: Interventional Cardiologist

YK: Interventional Cardiologist

YK: Interventional Cardiologist

TN: General Cardiologist

YG: Director of Cardiology

GK: Professor of Nagoya City University Graduate School of Medical Sciences HN: Director of Cardiology

\section{Competing interests}

The authors declare that they have no competing interests.

Received: 7 September 2010 Accepted: 11 November 2010 Published: 11 November 2010

\section{References}

1. Stamler J, Vaccaro O, Neaton JD, Wentworth D: Diabetes, other risk factors, and 12-yr cardiovascular mortality for men screened in the Multiple Risk Factor Intervention Trial. Diabetes Care 1993, 16:434-444.

2. Gerstein HC, Yusuf S: Dysglycaemia and risk of cardiovascular disease. Lancet 1996, 347:949-950.

3. Schernthaner $\mathrm{G}$ : Cardiovascular mortality and morbidity in type-2 diabetes mellitus. Diabetes Res Clin Pract 1996, 31(Suppl):S3-13.

4. Laakso M: Hyperglycemia and cardiovascular disease in type 2 diabetes. Diabetes 1999, 48:937-942.

5. Fujishima M, Kiyohara Y, Kato I, Ohmura T, Iwamoto H, Nakayama K, Ohmori S, Yoshitake T: Diabetes and cardiovascular disease in a prospective population survey in Japan: The Hisayama Study. Diabetes 1996, 45(Suppl 3):S14-16.

6. Tominaga M, Eguchi H, Manaka H, Igarashi K, Kato T, Sekikawa A: Impaired glucose tolerance is a risk factor for cardiovascular disease, but not impaired fasting glucose. The Funagata Diabetes Study. Diabetes Care 1999, 22:920-924.

7. Glucose tolerance and mortality: comparison of WHO and American Diabetes Association diagnostic criteria. The DECODE study group. European Diabetes Epidemiology Group. Diabetes Epidemiology:
Collaborative analysis Of Diagnostic criteria in Europe. Lancet 1999, 354:617-621.

8. Bartnik M, Malmberg K, Hamsten A, Efendic S, Norhammar A, Silveira A, Tenerz A, Ohrvik J, Ryden L: Abnormal glucose tolerance-a common risk factor in patients with acute myocardial infarction in comparison with population-based controls. J Intern Med 2004, 256:288-297.

9. Hashimoto K, Ikewaki K, Yagi H, Nagasawa H, Imamoto S, Shibata T, Mochizuki S: Glucose intolerance is common in Japanese patients with acute coronary syndrome who were not previously diagnosed with diabetes. Diabetes Care 2005, 28:1182-1186.

10. Ramachandran A, Chamukuttan S, Immaneni S, Shanmugam RM, Vishnu N, Viswanathan V, Jaakko T: High incidence of glucose intolerance in AsianIndian subjects with acute coronary syndrome. Diabetes Care 2005, 28:2492-2496.

11. Norhammar A, Tenerz A, Nilsson G, Hamsten A, Efendic S, Ryden L, Malmberg K: Glucose metabolism in patients with acute myocardial infarction and no previous diagnosis of diabetes mellitus: a prospective study. Lancet 2002, 359:2140-2144.

12. Bartnik M, Malmberg K, Norhammar A, Tenerz A, Ohrvik J, Ryden L: Newly detected abnormal glucose tolerance: an important predictor of longterm outcome after myocardial infarction. Eur Heart J 2004, 25:1990-1997.

13. Tamita K, Katayama M, Takagi T, Akasaka T, Yamamuro A, Kaji S, Morioka S, Kihara Y: Impact of newly diagnosed abnormal glucose tolerance on long-term prognosis in patients with acute myocardial infarction. Circ $J$ 2007, 71:834-841.

14. Report of the Expert Committee on the Diagnosis and Classification of Diabetes Mellitus. Diabetes Care 1997, 20:1183-1197.

15. Alberti KG, Zimmet PZ: Definition, diagnosis and classification of diabetes mellitus and its complications. Part 1: diagnosis and classification of diabetes mellitus provisional report of a WHO consultation. Diabet Med 1998, 15:539-553.

16. Lenzen M, Ryden L, Ohrvik J, Bartnik M, Malmberg K, Scholte Op Reimer W, Simoons ML: Diabetes known or newly detected, but not impaired glucose regulation, has a negative influence on 1 -year outcome in patients with coronary artery disease: a report from the Euro Heart Survey on diabetes and the heart. Eur Heart J 2006, 27:2969-2974.

17. Collaborative meta-analysis of randomised trials of antiplatelet therapy for prevention of death, myocardial infarction, and stroke in high risk patients. BMJ 2002, 324:71-86.

18. Peters RJ, Mehta SR, Fox KA, Zhao F, Lewis BS, Kopecky SL, Diaz R, Commerford PJ, Valentin V, Yusuf S: Effects of aspirin dose when used alone or in combination with clopidogrel in patients with acute coronary syndromes: observations from the Clopidogrel in Unstable angina to prevent Recurrent Events (CURE) study. Circulation 2003, 108:1682-1687.

19. Metoprolol in acute myocardial infarction (MIAMI): A randomised placebocontrolled international trial. The MIAMI Trial Research Group. Eur Heart $J$ 1985, 6:199-226.

20. Randomised trial of intravenous atenolol among 16027 cases of suspected acute myocardial infarction: ISIS-1. First International Study of Infarct Survival Collaborative Group. Lancet 1986, 2:57-66.

21. Yusuf S, Sleight P, Pogue J, Bosch J, Davies R, Dagenais G: Effects of an angiotensin-converting-enzyme inhibitor, ramipril, on cardiovascular events in high-risk patients. The Heart Outcomes Prevention Evaluation Study Investigators. N Engl J Med 2000, 342:145-153.

22. Fox KM: Efficacy of perindopril in reduction of cardiovascular events among patients with stable coronary artery disease: randomised, double-blind, placebo-controlled, multicentre trial (the EUROPA study). Lancet 2003, 362:782-788.

23. Randomised trial of cholesterol lowering in 4444 patients with coronary heart disease: the Scandinavian Simvastatin Survival Study (4S). Lancet 1994, 344:1383-1389.

24. Sacks FM, Pfeffer MA, Moye LA, Rouleau JL, Rutherford JD, Cole TG, Brown L, Warnica JW, Arnold JM, Wun CC, Davis BR, Braunwald E: The effect of pravastatin on coronary events after myocardial infarction in patients with average cholesterol levels. Cholesterol and Recurrent Events Trial investigators. N Engl J Med 1996, 335:1001-1009.

25. Prevention of cardiovascular events and death with pravastatin in patients with coronary heart disease and a broad range of initial cholesterol levels. The Long-Term Intervention with Pravastatin in 
Ischaemic Disease (LIPID) Study Group. N Engl J Med 1998, 339:1349-1357.

26. Ceriello A: The post-prandial state and cardiovascular disease: relevance to diabetes mellitus. Diabetes Metab Res Rev 2000, 16:125-132.

27. De Vriese AS, Verbeuren TJ, Van de Voorde J, Lameire NH, Vanhoutte PM: Endothelial dysfunction in diabetes. Br J Pharmacol 2000, 130:963-974.

28. Temelkova-Kurktschiev T, Henkel E, Koehler C, Karrei K, Hanefeld M: Subclinical inflammation in newly detected Type II diabetes and impaired glucose tolerance. Diabetologia 2002, 45:151

29. Node K, Inoue T: Postprandial hyperglycemia as an etiological factor in vascular failure. Cardiovasc Diabetol 2009, 8:23.

30. Knudsen EC, Seljeflot I, Michael A, Eritsland J, Mangschau A, Müller C, Arnesen H, Andersen GØ: Increased levels of CRP and MCP-1 are associated with previously unknown abnormal glucose regulation in patients with acute STEMI: a cohort study. Cardiovasc Diabetol 2010, 9:47.

31. Wallander M, Malmberg K, Norhammar A, Rydén L, Tenerz A: Oral glucose tolerance test: a reliable tool for early detection of glucose abnormalities in patients with acute myocardial infarction in clinical practice: a report on repeated oral glucose tolerance tests from the GAMI study. Diabetes Care 2008, 31:36-8.

32. Bartnik M, Rydén L, Malmberg K, Ohrvik J, Pyörälä K, Standl E, Ferrari R, Simoons M, Soler-Soler J, Euro Heart Survey Investigators: Oral glucose tolerance test is needed for appropriate classification of glucose regulation in patients with coronary artery disease: a report from the Euro Heart Survey on Diabetes and the Heart. Heart 2007, 93:72-7.

33. Bartnik M, Ryden L, Ferrari R, Malmberg K, Pyorala K, Simoons M, Standl E, Soler-Soler J, Ohrvik J: The prevalence of abnormal glucose regulation in patients with coronary artery disease across Europe. The Euro Heart Survey on diabetes and the heart. Eur Heart J 2004, 25:1880-1890.

34. Hu DY, Pan CY, Yu JM, China Heart Survey Group: The relationship between coronary artery disease and abnormal glucose regulation in China: the China Heart Survey. Eur Heart J 2006, 27:2573-9.

35. Sourij H, Saely CH, Schmid F, Zweiker R, Marte T, Wascher TC, Drexel H: Post-challenge hyperglycaemia is strongly associated with future macrovascular events and total mortality in angiographied coronary patients. Eur Heart J 2010, 31:1583-90.

36. Feinberg MS, Schwartz R, Tanne D, Fisman EZ, Hod H, Zahger D, Schwammethal E, Eldar M, Behar S, Tenenbaum A: Impact of the metabolic syndrome on the clinical outcomes of non-clinically diagnosed diabetic patients with acute coronary syndrome. Am J Cardiol 2007, 99:667-72.

37. Fisman EZ, Motro M, Tenenbaum A, Boyko V, Mandelzweig L, Behar S: Impaired fasting glucose concentrations in nondiabetic patients with ischemic heart disease: a marker for a worse prognosis. Am Heart J 2001, 141:485-90.

38. Anselmino M, Ohrvik J, Malmberg K, Standl E, Ryden L: Glucose lowering treatment in patients with coronary artery disease is prognostically important not only in established but also in newly detected diabetes mellitus: a report from the Euro Heart Survey on Diabetes and the Heart. Eur Heart J 2008, 29:177-184.

39. Dormandy JA, Charbonnel B, Eckland DJ, Erdmann E, Massi-Benedetti M, Moules IK, Skene AM, Tan MH, Lefebvre PJ, Murray GD, Standl E, Wilcox RG, Wilhelmsen L, Betteridge J, Birkeland K, Golay A, Heine RJ, Koranyi L, Laakso M, Mokan M, Norkus A, Pirags V, Podar T, Scheen A, Scherbaum W, Schernthaner G, Schmitz O, Skrha J, Smith U, Taton J: Secondary prevention of macrovascular events in patients with type 2 diabetes in the PROactive Study (PROspective pioglitAzone Clinical Trial In macroVascular Events): a randomised controlled trial. Lancet 2005, 366:1279-1289.

40. Chiasson JL, Josse RG, Gomis R, Hanefeld M, Karasik A, Laakso M: Acarbose treatment and the risk of cardiovascular disease and hypertension in patients with impaired glucose tolerance: the STOP-NIDDM trial. JAMA 2003, 290:486-494

41. Kragelund C, Snorgaard O, Køber L, Bengtsson B, Ottesen M, Højberg S, Olesen C, Kjaergaard JJ, Carlsen J, Torp-Petersen C, TRACE Study Group: Hyperinsulinaemia is associated with increased long-term mortality following acute myocardial infarction in non-diabetic patients. Eur Heart J 2004, 25:1891-7. doi:10.1186/1475-2840-9-75

Cite this article as: Kitada et al:: Post-load hyperglycemia as an important predictor of long-term adverse cardiac events after acute myocardial infarction: a scientific study. Cardiovascular Diabetology 2010 9:75.

\section{Submit your next manuscript to BioMed Central and take full advantage of:}

- Convenient online submission

- Thorough peer review

- No space constraints or color figure charges

- Immediate publication on acceptance

- Inclusion in PubMed, CAS, Scopus and Google Scholar

- Research which is freely available for redistribution

Submit your manuscript at www.biomedcentral.com/submit
Biomed Central 